\title{
Impact of the Covid-19 Pandemic on Otolaryngology Residency Training: A Cross-Sectional Study
}

\author{
Serafín Sánchez-Gómez ( $\nabla$ sanchezsg@us.es) \\ Hospital Universitario Virgen Macarena \\ Juan Manuel Maza-Solano \\ Hospital Universitario Virgen Macarena \\ Luz López-Flórez \\ Hospital General Universitario Gregorio Marañón \\ Pablo Parente Arias \\ Complexo Hospitalario Universitario A Coruña \\ David Lobo Duro \\ Marqués de Valdecilla University Hospital \\ José María Palacios-García \\ Hospital Universitario Virgen Macarena
}

\section{Research Article}

Keywords: Training, Otolaryngology, Surgical decline, Residents, COVID-19, Impact, Virtual training

Posted Date: April 23rd, 2021

DOI: https://doi.org/10.21203/rs.3.rs-437083/v1

License: (c) (1) This work is licensed under a Creative Commons Attribution 4.0 International License. Read Full License 


\section{Abstract}

\section{Background}

Training in surgical specialties has declined during the COVID-19 pandemic. A study was carried out to further analyze the impact of the COVID-19 pandemic on specific aspects of clinical, training, and research activities performed by the otolaryngology residents in Spain.

\section{Methods}

A cross-sectional qualitative study was conducted during the last two weeks of February 2021. The study consisted of an online survey taken by otolaryngology residents who had undertaken one-year continuing training from February 15, 2020 to February 15, 2021 and consisted of 26 questions exploring the impact of the COVID-19 on the health of the ENT residents and training activities. Categorical variables were reported as frequency and percentage. When indicated, Pearson's Chi-square test (c2) with Yates's correction and Pearson's correlation coefficient (r) were used.

\section{Results}

143 completed surveys were received from 264 Residents (54.17\%). 36 residents (25.2\%) have suffered from the disease due to SARS-CoV-2. Most of them only developed mild symptoms (86.1\%), with 3 requiring hospitalization (8.3\%). The origin of infection was unknown in all cases and the need for confinement was principally due to either attending an asymptomatic patient in 9 cases (6.3\%) or to being in close contact with an asymptomatic person off hospital grounds in 22 (15.4\%). $60.1 \%$ of the residents surveyed reported having lost more than 6 months of their training period, and in $18.8 \%$ of cases, it was as high as 10 and 12 months. There has been a reduction of more than $75 \%$ of what was planned in surgical training $(p<0.05)$ of tympanoplasty, mastoidectomy, stapedectomy, cochlear implants, endoscopic sinonasal and anterior skull base surgery, septoplasty and turbinoplasty.

\section{Conclusions}

The decline in ENT activity and residents having to assist in other COVID-19 units during the most critical moments of the pandemic, has caused the main reduction in their training capacity. Virtual activities have been widely accepted, but they have not completely replaced all residents' training needs. Specialized ENT training should be extended from 6 months to 1 year to ensure adequate training, especially for recovering the surgical Otology and Rhinology hands-on training lost during the pandemic.

\section{Background}

The COVID-19 pandemic caused by the SARS-CoV-2 virus [1, 2] has had a significant impact on specialized medical training [3] associated with physician trainee concern over missed educational opportunities [4]. An elevated number of daily care activities have been cancelled and many healthcare professionals forced to support Departments and hospital units overwhelmed by the rapid spread and intensity of the pandemic. ENT departments have had to segregate some of the residents performing face-to-face clinical activities, while others have been made to quarantine at home [5]. At the beginning of the pandemic, addressing the uncertainty on the transmission mechanisms of the virus and overcoming a shortage of personal protective equipment became the main priorities. Clinical pathways and hospital structures were redesigned to assist patients affected by COVID-19, to the detriment of the assistance given to nonCOVID-19 patients [6]. Many hospitals and healthcare centers were forced to cancel non-urgent surgical interventions due to the lack of hospital beds and the temporary use of operating rooms and post-anesthetic recovery rooms as ICU beds [7]. The number of patients who visited the ENT Departments for any other pathology was substantially reduced due to restrictions on population mobility and limited access to primary care centers [8].

The ENT Departments quickly implemented novel training models that complied with the restrictions imposed by the pandemic [9]. The aim was to mitigate the training deficiencies derived from the elimination of face-to-face activities [10], while following the protective measures recommended by health and scientific institutions [9-10, 11]. Innovative virtual communication solutions were implemented, taking advantage of many software tools available on the internet. Furthermore, new simulation-based training approaches were promoted to counteract the reduction of surgical procedures [12, 13].

By the end of May 2020, both society at large and healthcare systems perceived that the spread of the virus was under control. At that moment, the impact that the COVID-19 pandemic was having on otolaryngology residents' training began to be noticed [14-17. However, the lack of knowledge about the transmission mechanisms of the disease and the huge pressure exerted by different social, political, and economic agents to prematurely relax the containment measures, revealed that the outbreak of spring 2020 had only been a first wave. This was to be followed by a second wave of greater intensity, although with a slower onset and decline than the first wave, and then by a third wave, which was much more intense than the previous two, without normality being regained at any moment. The incidence of each of these three waves lasted longer in Spain than in other European countries, although with a wide geographical variability between different Spanish regions [2].

The first publications addressing the effect of the COVID-19 pandemic on ENT training only considered the effect of the first wave during the spring of 2020 [9]. One year after the onset of the first outbreak, the true impact of the pandemic on Spanish otolaryngology residents during a time period equivalent to one year of their training program can be now assessed. This knowledge is especially relevant in those countries in which the training of a surgical specialty, such as otolaryngology, is limited to a four-year program, as is in the case of Spain. The aim of this study is to further analyze the impact of the COVID-19 pandemic on specific aspects of the broad range of clinical, training, and research activities performed by the otolaryngology residents in Spain, as well as the solutions used to mitigate the deficiencies caused by the pandemic and the new virtual training models adopted.

\section{Material And Methods}




\section{Study design}

A cross-sectional qualitative study was conducted during the last two weeks of February 2021. The study consisted of an online survey taken by otolaryngology residents of the Spanish teaching units who had undertaken one-year continuing training from February 15, 2020 to February $15,2021$.

In Spain, there have been a succession of time periods of increased COVID-19 incidence. These have become known as waves and can be defined as the periods between the increase and decrease of the number of positive cases diagnosed for SARS-CoV- 2 by PCR (>10\% of the prevalent cases in the previous 14 days). Thus, the first wave can be said to have occurred between March 10 and May 10, 2020; the second wave between September 1 and November 16, 2020; and the third wave between December 11, 2020 and February 15, 2021.

\section{Population}

The population under study included otolaryngology residents who had obtained their position in 2017, 2018, 2019 and 2020 (PGY4, PGY3, PGY2 and PGY1 respectively) in any of the 77 accredited Otolaryngology Academic Units in Spain, all of which belong to the Public Health System, except for one unit from the private health sector. All hospitals involved treated both COVID-19 and non-COVID-19 patients throughout the study time. The residents from year 2016 were excluded from the study since they had only experienced the impact of the pandemic between March 10 and May 20, 2020, when their residency program was drawing to an end.

\section{Survey design}

The survey was carried out through Google Forms and consisted of 26 questions divided in 8 sections: 1) geographical location of the hospital by region and city; 2) impact of the COVID-19 on the health of the ENT residents and diagnostic testing they had undergone; 3) impact on the hospital clinical activity; 4) global impact on the overall change of theoretical training activities, especially by areas of specialty, including new virtual training models; 5 ) global impact on practical training activities by areas of specialty; 6 ) impact on internal and external rotations, courses, congresses, visits to other hospitals, etc.; 7 ) impact on research activities; and 8) global impact on skills acquisition as an ENT specialist.

\section{Survey distribution and data collection}

An email message was sent to all the otolaryngology residents in Spain informing them of the aim and scope of the study, including a link to the web page where the survey could be found. Before participating, the residents' consent was obtained.

\section{Validation of the survey questionnaire}

The variables measuring the impact of the COVID-19 pandemic on the activities of residency programs constituted the main part of the questionnaire. They were measured using a 4-point Likert scale, which was validated using the Pearson correlation method ( $\rho)$, with a confidence level of $95 \%$.

The reliability of the survey was verified through a value of $a=0.812$ in the Cronbach's alpha test for 5 items. The variables used to measure the impact of the COVID-19 pandemic on ENT residency programs were thus shown to be consistent and they would have led to the same results if used more than once. The validity of the demographic variables and those collecting nominal and ordinal information was not evaluated, since they included participants' personal information.

\section{Statistical analysis}

Statistical analysis was performed with Statistical Package for Social Sciences, version 26 (SPSS, Chicago, IL, USA). Categorical variables were reported as frequency and percentage. The comparison between the different levels of the impact of the COVID-19 pandemic on the training of ENT residents was assessed using Pearson's Chi-square test $\left(\chi^{2}\right)$ with Yates's correction. Statistical significance was determined by a $p$-value cutoff of 0.05 with a $95 \%$ confidence interval. The relationship between COVID-19 incidence and the number of residents who suffered the disease was assessed by the Pearson's correlation coefficient (r).

\section{Results}

143 completed surveys were received from a total of 264 residents, giving a response rate of $54.17 \%$ (62.8\% women), with a margin of error of $5.56 \%$ for a confidence interval of $95 \%$. They were received from 59 out of the 77 accredited ENT-specialized training departments (76.6\%) in 15 of the 17 Spanish autonomous regions (88.2\%). The survey was taken by 18 of 81 PGY4 (22.2\%), 36 of 69 PGY3 (52.2\%), 43 of 63 PGY2 (68.2\%) and 46 of 51 PGY1 (90.2\%).

A total of 36 residents (25.2\%) have suffered from the disease due to SARS-CoV-2, 14 in the first wave (38.9\%), 12 in the second wave (33.3\%) and 10 in the third wave (27.7\%). Of these, 31 only had mild symptoms and did not require medical attention (86'1\%), 3 were hospitalized due to severe symptoms (8.3\%) and 2 had moderate symptoms that required medical attention without hospitalization (5.6\%). No resident was admitted to an ICU. The intensity of the affectation meant that 14 were absent from work between 0 and 14 days, 19 did so between 15 and 30 days and 3 between 31 and 60 days. Figure 1 and Fig. 2 show the number of ENT residents who have suffered from COVID-19 disease during the three waves in Spain by geographical location and the incidence recorded in the regions: 12 cases in Madrid (33.3\%), 6 in Andalusia (16.6\%), 4 in Valencia (11.1\%), 3 in Aragón (8.3\%), 2 in Canarias (5.6\%), 2 in Castilla La-Mancha (5.6\%), 2 in Extremadura (5.6\%), 2 in Murcia (5.6\%), 1 in Castilla-León (2.8\%), 1 in La Rioja (2.8\%) and 1 in País Vasco (2.8\%). No relationship between COVID-19 incidence by region and the number of residents who suffered the disease was found $(r=0,35)$. The origin of infection was unknown in all cases and the need for confinement was principally due to either attending an asymptomatic patient in 9 cases (6.3\%) or to being in close contact with an asymptomatic person off hospital grounds in $22(15.4 \%)$.

The impact of COVID-19 on residents' health and their levels of absence from work is shown in Table 1. 
Figure 3 shows the global impact of each subarea of the specialty, while the specific impact on the surgical activity of the most relevant procedures for specialized training is shown in Table 2: 10 out of 15 surgical procedures showed a significant decrease in training for the respective year of residency, except for the increase seen between PGY1 and PGY2. The impact on face-to-face training and research activities is shown in Table 3.

All residents (100\%) answered that their training had been reduced as a result of the pandemic: 23 (16\%) recognized that they had suffered maximum impact, $73(51 \%)$ a very high impact, $40(27.9 \%)$ an intermediate impact and 7 (4.9\%) a low impact. Figure 4 illustrates the residents' perception on the amount of time lost on training due to the COVID-19 pandemic. The 7 residents (4.9\%) who had not seen their training substantially altered proposed that legal or regulatory modifications to the training program should not be introduced, while $54(37.7 \%)$ expressed the need to extend the residency program for 1 year more, 22 (15.3\%) were in favor of extending it for 6 months, and 19 (13.2\%) for 3 months, whereas 41 (28.6\%) considered that the training program should be extended depending on the deficiencies and particular needs of each resident.

\section{Discussion}

A response rate of $54.17 \%$ is sufficiently representative of the population under study, including the participation of ENT residents from all across Spain and from different years of their residency program.

Spain, with a population of 3,149,012 infected people and a transmission rate of $6.65 \%$, is the fourth European country with the highest incidence of confirmed cases of SARS-CoV-2 as of March 8, 2021 behind Russia, the United Kingdom, and France [18]. In this situation, a great impact on health care and training of residents was expected.

\section{Impact on residents' health}

Spain is one of the countries whose health professionals have most suffered from COVID-19, with 125,691 professionals infected as of March 8, 2021 [2]. Specifically, $16.5 \%$ of otolaryngologists had been infected by the beginning of the third wave [19], having a contagion rate 2.48 times higher than that of the general population. In the case of otolaryngology residents, our study found that $25.2 \%$ had been infected, giving an infection rate 3.79 times higher than that of the general population and 1.53 times higher than that shown in ENT specialists, albeit with the limitation that the incidence of the third wave was not included in the study of Martin-Villares et al. [19].

Madrid, Andalusia, and Valencia, the regions with the highest transmission rates in Spain, exhibited the highest number of COVID-19 cases among otolaryngology residents. This may be due to there being a higher number of residents in these regions, even though the region of Andalusia reported a lower incidence than the other two (Fig. 2). Surprisingly, none of the 15 residents surveyed in Catalonia (10.5\% of the sample), a region with a transmission rate similar to that of the three aforementioned regions, reported having had a COVID-19 infection. This outcome could be caused by a nonresponse bias or to residents having taken more restrictive measures both inside and outside the hospital, given the high incidence rate in Catalonia. All surveyed residents answered that they had undergone appropriate SARS-CoV-2 diagnostic testing when necessary. In this sense, there have not existed difficulties in accessing clinical testing, so that all cases have actually been diagnosed.

Shortages of personal protective equipment and lack of knowledge of the transmission mechanisms of the disease may account for $38.9 \%$ of the residents who were infected in the first wave [20]. However, these circumstances cannot explain the $33.3 \%$ and $27.7 \%$ of residents who were infected in the second and third waves, respectively. Although the residents who suffered from COVID-19 were unable to identify the origin of their infection, in no case did it come from their having treated a positive SARS-CoV-2 patient. This suggests that awareness of a patient's positive SARS-CoV-2 condition promoted residents to adequately protect themselves during health care activities [21]. However, residents did not seem to rigorously adopt self-protection measures when attending asymptomatic patients, and 9 of them (6.3\%) had to isolate after being in close contact with a patient whose positive diagnosis was later confirmed. Nevertheless, the main circumstance for self-isolation among residents, in 22 cases (15.4\%), was the fact that they had been in close contact with an asymptomatic person off hospital grounds. This yields an incidence rate similar to that found in the general population, explained by the fact that the second and third waves affected young people more prominently than did the first wave (see Fig. 1 and Fig. 2).

\section{Factors causing loss of training}

The disruption in training suffered by ENT residents during the pandemic cannot be fully explained by residents being on sick leave or preventive isolations due to close contact with positive SARS-CoV-2 and/or asymptomatic patients. The healthcare activities performed in other clinical units during the pandemic emergency and the reduction of the ENT activity itself have been the main causes of reduced training and the perception among many residents that a variable number of months of their residency program had been lost, depending on individual circumstances and local incidences. It is noteworthy that $60.1 \%$ of the residents surveyed reported having lost more than 6 months of their training period, and in $18.8 \%$ of cases, it was as high as 10 and 12 months. Such a disruption is especially serious in ENT residency programs that only cover 4 years of specialized training.

Restrictions on citizen's geographical mobility and social distancing, including health professionals, have caused the cancellation of more than two thirds of the rotations, courses, and stays in other hospitals. This has notably restrained the residents' skills at the end of their training period, which are limited to those developed in their hospital of origin.

\section{Impact on training activities}

The decrease of in-person theoretical training activities has not been completely replaced by virtual sessions, webinars, and videoconferences. Although this obligatory new format has found wide acceptance among residents and will be included as part of their daily activities in the future, face-to-face sessions seem to encourage motivation in theoretical training activities for both trainees and trainers. The interest shown by $11.1 \%$ of the residents in using virtual surgery as a training methodology must be also highlighted, which will stimulate the development of this tool. Otology and rhinology are the ENT areas in 
which reductions in theoretical activities during the pandemic have been the most drastic. Specifically, a reduction of more than $75 \%$ was reported in $50 \%$ and $39 \%$ of residents, respectively, for each of these ENT subspecialties.

The transformation of all ENT congresses into a virtual format has increased the participation of many residents compared with previous face-to-face situations, allowing them to produce more oral communications, posters, and videos, as well as increasing the production of scientific articles. However, the research activities that required the performance of face-to-face activities with patients or in the laboratory have been delayed (37.1\%) or cancelled (4.9\%).

Whereas exploratory and diagnostic procedures have been less affected, the most notable deficiency in the training of ENT residents during the pandemic has been caused by the decrease of surgical procedures (Table 1). The cancellation or delay in surgical interventions, which are essential procedures in the training of ENT residents both in type and number [22-24], was one of the first and most widespread recommendations of scientific societies at the outbreak of the pandemic. Thus, $64 \%$ of residents have stopped intervening as a primary surgeon in more than $75 \%$ of the procedures planned by their residency program. This interruption has been applied to residents in all years of residency. However, since their time to recover the skills not developed is more limited, residents from the second and the third years may be more affected.

The surgical procedures with a lower margin of recovery are the otological (myringoplasty, tympanoplasty with mastoidectomy, stapedectomy, cochlear implants) and the rhinological procedures (endoscopic sinonasal and anterior skull base surgery, septoplasty, turbinoplasty), which are also those that have been most affected by the decrease in theoretical training activities. In fact, these procedures constitute the main body of surgical knowledge for ENT residents' training [25]. The withdrawal of surgical simulations with cadavers, a fundamental basis of ENT surgical training, has also been very relevant for the reduction of experience in surgical hands-on learning. Nevertheless, $43 \%$ of the residents increased their learning in performing tracheotomies by more than $75 \%$, despite the fact that the initial recommendations established that it was not suitable for residents. The systematic reduction of oncological surgeries caused by restrictions on citizen's geographical mobility and limited access to primary care centers has mainly affected PGY3 and PGY4 trainees, who perform many of these procedures as primary surgeons. Due to the decline of their daily clinical activity, there have been more PGY1 and PGY2 in the operating room than usual who have been able to increase their operating room experience in an unplanned way. The recommendations of health institutions to perform PCR tests to detect asymptomatic patients between 24 and 72 hours before surgeries and the increase of outpatient surgical interventions [26] has theoretically allowed many ENT Departments to increase their surgical activity. However, this possibility was indeed restricted by the shortage of operating rooms and hospital beds, massively occupied by COVID-19 patients over long periods of time during the pandemic.

\section{Loss of time on residents' training and proposal for recovery}

Except for a few cases of residents from hospitals less affected by the pandemic, who have not seen their training program substantially altered, $53 \%$ are in favor of extending their residency by at least 6 months, while 37.7\% of them believe it necessary to extend it by a full year [27]. Although these numbers demonstrate that the duration and intensity of the pandemic have impacted residents at different levels depending on their location, these numbers are sufficiently conclusive and well supported so as to oblige health authorities to implement measures to alleviate training shortcomings and deficiencies [28].

The results reveal the need for modifying the current ENT training programs in Spain, currently exclusively supervised by the local teaching units of each hospital. More comprehensive ENT residency programs should be designed and approved at a national level in order to guarantee equal access of all residents irrespective of the hospital where they develop their training program. Novel virtual teaching and simulated-based methodologies should also be proposed and coordinated at a national level to mitigate the shortcomings of local ENT departments in specific situations, such as those experienced during the pandemic $[29,30]$.

\section{Conclusions}

Most residents who have suffered from COVID-19 only developed mild symptoms, with few cases requiring hospitalization. The origin of infection was unknown in all cases and the need for confinement was principally due to either attending an asymptomatic patient or to being in close contact with an asymptomatic person off hospital grounds. However, the decline in ENT activity and residents having to assist in other COVID-19 units during the most critical moments of the pandemic, has caused the main reduction in their training capacity. Residents must rigorously comply with the protection measures recommended against COVID-19 when treating patients, especially those who show no symptoms.

Although the change from face-to-face activities to virtual activities has been widely accepted, they have not completely replaced all residents' training needs to ensure adequate ENT residency training. The loss of between 6 and 12 months of the training program has considerably affected the residents' skills development as ENT specialists, particularly in the case of surgical hands-on training. It may be necessary to extend residency programs from 6 to 12 months in order to diminish such training deficiencies, especially in those areas most strongly affected, such as otology and rhinology, in which more than $75 \%$ of interventions of myringoplasty, tympanoplasty with mastoidectomy, stapedectomy, cochlear implants, sinonasal endoscopic surgery, anterior skull base surgery, septoplasty and turbinoplasty have been cancelled.

\section{List Of Abbreviations}

ICU Intensive Care Unit

ENT Ear, Nose and Throat

PCR Polymerase Chain Reaction

PGY-1 Postgraduate year one, First year resident 
PGY-2 Postgraduate year two, Second year resident

PGY-3 Postgraduate year three, Third year resident

PGY-4 Postgraduate year four, Fourth year resident

\section{Declarations}

\section{Ethics approval and consent to participate}

All methods were carried out in accordance with relevant guidelines and regulations. Survey was conducted after approval by Hospital Universitario Virgen Macarena Ethics Committee.

Informed consent was obtained from all participants.

\section{Consent for publication}

Consent for publication was obtained from all participants.

\section{Availability of data and materials}

The datasets used and/or analyzed during the current study are available from the corresponding author on reasonable request.

\section{Competing interests}

The authors declare that they have no competing interests.

\section{Funding}

Not applicable.

\section{Authors' contributions}

All authors contributed to the study conception and design. Material preparation, data collection and analysis were performed by SSG and JMMS. JMPG conducted the statistical analysis. The first draft of the manuscript was written by SSG and all authors commented on previous versions of the manuscript. All authors read and approved the final manuscript. The views in this article are those of the authors and do not necessarily represent the official views of the Spanish Society of Otorhinolaryngology, Head and Neck Surgery.

\section{Acknowledgements}

Not applicable.

\section{Author details}

SSG is Chair of the Department of Otorhinolaryngology, Hospital Universitario Virgen Macarena; President of the ENT Training Commission, Spanish Society of Otorhinolaryngology, Head and Neck Surgery (SEORL-CCC). sanchezsg@us.es. orcid.org/0000-0002-5897-7821

JMMS is otolaryngologist; President of the Protocols and Standards Commission, Spanish Society of Otorhinolaryngology, Head and Neck Surgery (SEORLCCC).jmaza@us.es. orcid.org/0000-0002-3588-9095

LLF is otolaryngologist; President of the Residents' Commission, Spanish Society of Otorhinolaryngology, Head and Neck Surgery (SEORL-CCC). luzlflorez@gmail.com. https://orcid.org/0000-0002-9221-3630

PPA is otolaryngologist; President of the International Relationships Commission, Spanish Society of Otorhinolaryngology, Head and Neck Surgery (SEORLCCC).plparente@gmail.com. orcid.org/0000-0003-3889-3177

DLD is otolaryngologist; Member of the Spanish Society of Otorhinolaryngology, Head and Neck Surgery (SEORL-CCC). david.lobo@scsalud.es. orcid.org/0000-0002-4322-6638

JMPG is otolaryngologist, Member of the Spanish National Commission on Otorhinolaryngology. orlpalaciosgarcia@gmail.com. orcid.org/0000-0003-31461910

\section{References}

[1] World Health Organization (WHO). WHO Coronavirus (COVID-19) Dashboard [Internet]. Available from: https://covid19.who.int. (2021). Accessed 10 April 2021.

2 Carlos III Health Institute. Spanish Ministry of Science and Innovation. COVID-19 Reports [Internet]. Available from: http://bit.ly/3leGMWs. (2021). Accessed 10 April 2021. 
3 Ellison EC, Spanknebel K, Stain SC, Shabahang MM, Matthews JB, Debas HT, et al. Impact of the COVID-19 Pandemic on Surgical Training and Learner WellBeing: Report of a Survey of General Surgery and Other Surgical Specialty Educators. J Am Coll Surg. 2020;231(6):613-626. https://doi.org/ 10.1016/j.jamcollsurg.2020.08.766

4 Lou SS, Goss CW, Evanoff BA, Duncan JG, Kannampallil T. Risk factors associated with physician trainee concern over missed educational opportunities during the COVID-19 pandemic. BMC Medical Education. 2021;21:216. https://doi.org/10.1186/s12909-021-02665-0

5 Lucey CR, Johnston SC. The Transformational Effects of COVID-19 on Medical Education. JAMA. 2020;324(11):1033-1034. https://doi:10.1001/jama.2020.14136

6 Maza-Solano JM, Plaza-Mayor G, Jiménez-Luna A, Parente-Arias P, Amor-Dorado JC. Strategies for the practice of otolaryngology and head and neck surgery during the monitoring phase of COVID-19. Acta Otorrinolaringol Esp. 2020;71(6):367-378. https://doi:10.1016/j.otorri.2020.05.001

7 Haldane V, Zhang Z, Abbas RF, Dodd W, Lau LL, Kidd MR, Rouleau K, Zou G, Chao Z, Upshur REG, Walley J, Wei X. National primary care responses to COVID19: a rapid review of the literature. BMJ. 2020;Open 8;10(12):e041622. https://doi.org/10.1136/bmjopen-2020-041622

8 Kamerow D. Covid-19: don't forget the impact on US family physicians. BMJ. 2020;368:m1260. https://doi.org/10.1136/bmj.m1260

9 Bandi F, Karligkiotis A, Mellia J, Gallo S, Turri-Zanoni M, Battaglia P, Castelnuovo. Strategies to overcome limitations in Otolaryngology residency training during the COVID-19 pandemic. Eur Arch Otorhinolaryngol. 2020;277(12):3503-3506. https://doi:10.1007/s00405-020-06228-9

10 Crosby DL, Sharma A. Insights on Otolaryngology Residency Training during the COVID-19 Pandemic. Otolaryngol Head Neck Surg. 2020;163(1):38-41. https://doi:10.1177/0194599820922502

11 Shah JP. The impact of COVID-19 on Head and Neck surgery, education, and training. Head Neck. 2020;42(6):1344-1347. https://doi:10.1002/hed.26188

[1]2 Okland TS, Pepper JP, Valdez TA. How do we teach surgical residents in the COVID-19 era? J Surg Educ. 2020;77(5):1005-1007. https:// doi:10.1016/j.jsurg.2020.05.030

[1]3 Favier V, Kimmoun A, Gatin A, Gallet P. Percutaneous tracheostomy simulation training for ENT physicians in the treatment of COVID-19-positive patients. European Annals of Otorhinolaryngology, Head and Neck Diseases. 2020;137(4). https://doi.org/10.1016/j.anorl.2020.06.002

[1]4 Cai Y, Jiam NT, Wai KC, Shuman EA, Roland LT, Chang JL. Otolaryngology Resident Practices and Perceptions in the Initial Phase of the U.S. CoVID-19 Pandemic. Laryngoscope. 2020;130(11):2550-2557. https://doi:10.1002/lary.28733

[1]5 De Luca P, Colacurcio V, De Bonis E, Petrosino M, Bisogno A, Troisi D, Calvanese M, Marra P. Impact of the COVID-19 Pandemic on Otolaryngology Residency: A Real-Life Experience. Ear Nose Throat J. 2020;99(9):563-564. https://doi:10.1177/0145561320926291

[1]6 Álvarez ML, Waissbluth S, González C, Napolitano C, Torrente M, Délano PH, Alarcón R, Fernández F, Bitrán R. How the COVID-19 pandemic affects specialty training: An analysis of a nationwide survey among otolaryngology residents in Chile. Medwave. 2021;21(1):e8098.

https://doi:10.5867/medwave.2021.01.8097

[1]7 Comer BT, Gupta N, Mowry SE, Malekzadeh S. Otolaryngology Education in the Setting of COVID-19: Current and Future Implications. Otolaryngol Head Neck Surg. 2020;163(1):70-74. https://doi:10.1177/0194599820923621

18 Center for the Coordination of Health Alerts and Emergencies. Ministry of Health of Spain. Update No. 326. Coronavirus disease (COVID-19) [Internet]. 08.03.2021. Available from: https://bit.ly/30y7BM2. (2021). Accessed 10 April 2021.

19 Martin-Villares C, Bernal-Sprekelsen M, Molina-Ramirez CP, Bartolome-Benito M; COVID ORL ESP Collaborative Group. Risk of contagion of SARS-CoV-2 among otorhinolaryngologists in Spain during the "Two waves". Eur Arch Otorhinolaryngol. 2021;1-7. https://doi:10.1007/s00405-020-06582-8

20 Alshdaifat E, Sindiani A, Khasawneh W, Abu-Azzam O, Qarqash A, Abushukair H, Obeida N. The impact of COVID-19 pandemic on training and mental health of residents: a cross-sectional study. BMC Medical Education. 2021;21:208. https://doi.org/10.1186/s12909-021-02655-2

21 Mick P, Murphy R. Aerosol-generating otolaryngology procedures and the need for enhanced PPE during the COVID-19 pandemic: a literature review. J Otolaryngol Head Neck Surg. 2020;49(1):29. https://doi:10.1186/s40463-020-00424-7

22 Accreditation Council for Graduate Medical Education (ACGME). Required Minimum Number of Key Indicator Procedures for Graduating Residents. Review Committee for Otolaryngology - Head and Neck Surgery [Internet]. Available from: https://bit.ly/3dtNXbB. (2020). Accessed 10 April 2021.

23 European Union of Medical Specialists (UEMS). Logbook Oto-Rhino-Laryngology Surgery (Revision 2020). Training Programme [Internet]. Available from: https://bit.ly/3vISAuU. (2020). Accessed 10 April 2021.

24 Ministry of Health of Spain. Order SCO / 1262/2007, of April 13, approving and publishing the training program for the specialty of Otolaryngology [Text in Spanish] [Internet]. Available from: https://www.boe.es/eli/es/o/2007/04/13/sco1262. (2008). Accessed 10 April 2021. 
25 Suárez C, Sánchez S, Cobeta I. Analysis of the otorhinolaryngology services authorized for the training of residents. Acta Otorrinolaringol Esp. 2009;60(5):364-71. https://doi:10.1016/S2173-5735(09)70158-9

26 Recommendations for the programming of surgery under safe conditions during the transition period of the COVID-19 pandemic. Version June 2, 2020 [Article in Spanish] [Internet]. Available from: https://bit.ly/3crDFXr. (2020). Accessed 10 April 2021.

27 Munro C, Burke J, Allum W, Mortensen N. Covid-19 leaves surgical training in crisis. BMJ. 2021;372:n659. https://doi:10.1136/bmj.n659

28 Lo HY, Lin SC, Chaou CH, Chang YC, Ng CJ, Chen SY. What is the impact of the COVID-19 pandemic on emergency medicine residency training: an observational study. BMC Medical Education. 2020;20:348. https://doi.org/10.1186/s12909-020-02267-2

29 Rubin R. COVID-19's Crushing Effects on Medical Practices, Some of Which Might Not Survive. JAMA. 2020;324(4):321-323.

30 Karunaratne D. 12 Tips to Improve ENT Training During the Covid-19 Pandemic. MedEdPublish. 2021;10[1]:59. https://doi:10.15694/mep.2021.000059.1

\section{Tables}


Table 1 Impact of the COVID-19 pandemic on residents' health, absence from work, and dedication to ENT activities

\begin{tabular}{|c|c|}
\hline $\begin{array}{l}\text { Residents who have suffered from COVID-19 } \\
\text { Mild }\end{array}$ & $\begin{array}{l}36(25.2 \%) \\
31(86.1 \%)\end{array}$ \\
\hline Moderate (required medical attention) & $2(5.6 \%)$ \\
\hline Severe (required hospitalization) & $3(8.3 \%)$ \\
\hline Residents who have not suffered from COVID-19 & $107(74.8 \%$ \\
\hline \multicolumn{2}{|l|}{ Diagnostic tests } \\
\hline \multicolumn{2}{|l|}{ Performed in symptomatic residents for COVID-19 diagnosis } \\
\hline PCR test & $26(72.2 \%)$ \\
\hline Antibody test & $10(27.8 \%)$ \\
\hline Performed in symptomatic residents to determine whether they have passed the infection & $32(94.1 \%)$ \\
\hline \multicolumn{2}{|l|}{ Performed in asymptomatic residents suspected of having COVID-19 } \\
\hline At least one PCR test & $102(97.1 \%$ \\
\hline More than one PCR test & $98(85.8 \%)$ \\
\hline At least one antigen or antibody test & $107(100 \%)$ \\
\hline \multicolumn{2}{|l|}{ Absence from work } \\
\hline No absence & $49(34.3 \%)$ \\
\hline \multicolumn{2}{|l|}{ Due to COVID-19 } \\
\hline $0-14$ days & $14(9.8 \%)$ \\
\hline 15-30 days & $19(13.3 \%)$ \\
\hline 30-60 days & $3(2.1 \%)$ \\
\hline \multicolumn{2}{|l|}{ Due to confinement ${ }^{\mathrm{a}}$} \\
\hline $0-14$ days & $35(24.5 \%)$ \\
\hline 15-30 days & $14(9.8 \%)$ \\
\hline 30-60 days & $3(2.1 \%)$ \\
\hline 60-90 days & $4(2.8 \%)$ \\
\hline \multicolumn{2}{|l|}{ Residents' dedication to ENT activities in the pandemic } \\
\hline Full dedication to ENT activities & $69(48.3 \%)$ \\
\hline Partial dedication to the Emergency Room & $33(23.1 \%)$ \\
\hline Partial dedication to Internal Medicine & $18(12.6 \%)$ \\
\hline Partial dedication to other COVD-19 units & $19(13.3 \%)$ \\
\hline Partial dedication to ICU & $1(0.7 \%)$ \\
\hline \multicolumn{2}{|l|}{ Completion of ENT residency programs as scheduled before the pandemic } \\
\hline Full completion & $41(28.7 \%)$ \\
\hline $80-100 \%$ completion & $49(34.3 \%)$ \\
\hline $60-80 \%$ completion & $29(20.3 \%)$ \\
\hline $40-60 \%$ completion & $16(11.2 \%)$ \\
\hline $20-40 \%$ completion & $6(4.2 \%)$ \\
\hline$<20 \%$ completion & $1(0.7 \%)$ \\
\hline
\end{tabular}

${ }^{a}$ Reasons for confinement: a) Close contact with a SARS-CoV-2 positive patient without adequate protection b) Having treated a SARS-CoV-2 positive patient without adequate protection; c) Testing negative for PCR in a suspicious patient

2 Number of residents affected on surgical activity during the COVID-19 pandemic

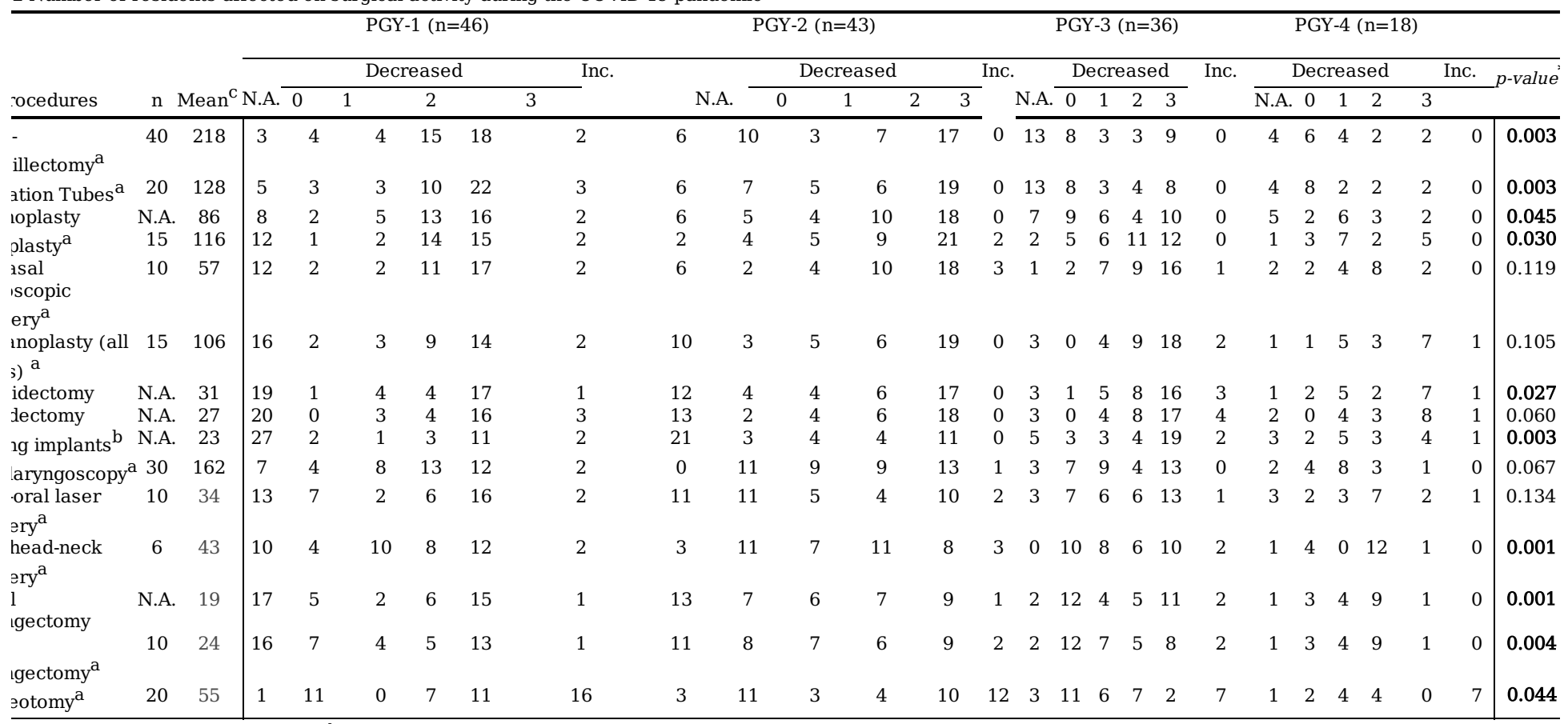

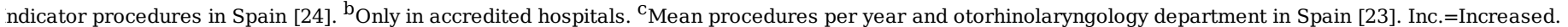

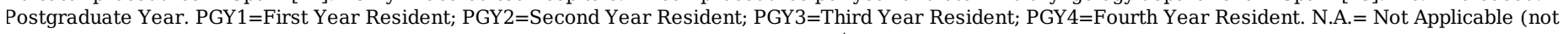
uled in the residency program that year). $0=<25 \% ; 1=25-50 \% ; 2=50-75 \% ; 3=75-100 \%$. * $p$-value cutoff of 0.05 (c2, Yates's correction) 
Table 3 Impact on face-to-face training and research activities

\begin{tabular}{|c|c|}
\hline \multicolumn{2}{|l|}{ Scheduled training activities } \\
\hline Maintenance of all scheduled training activities & $16(11.2 \%)$ \\
\hline Reduction of training programs & $127(88.8 \%)$ \\
\hline Suspension of internal rotations & $98(68.5 \%)$ \\
\hline Suspension of courses and visits to other hospitals & $127(88.8 \%)$ \\
\hline \multicolumn{2}{|l|}{ Impact on clinical sessions } \\
\hline $75-100 \%$ cancelled & $47(32.8 \%)$ \\
\hline $50-75 \%$ cancelled & $37(25.9 \%)$ \\
\hline $25-50 \%$ cancelled & $31(21.7 \%)$ \\
\hline$<25 \%$ cancelled & $28(19.6 \%)$ \\
\hline \multicolumn{2}{|l|}{ Impact on bibliographic sessions } \\
\hline $75-100 \%$ cancelled & $56(39.1 \%)$ \\
\hline $50-75 \%$ cancelled & $33(23.1 \%)$ \\
\hline $25-50 \%$ cancelled & $24(16.8 \%)$ \\
\hline$<25 \%$ cancelled & $30(20.9 \%)$ \\
\hline \multicolumn{2}{|l|}{ Impact on theoretical sessions } \\
\hline $75-100 \%$ cancelled & $57(39.8 \%)$ \\
\hline $50-75 \%$ cancelled & $36(25.2 \%)$ \\
\hline $25-50 \%$ cancelled & $18(12.6 \%)$ \\
\hline$<25 \%$ cancelled & $32(22,4 \%)$ \\
\hline \multicolumn{2}{|l|}{ Virtual training activities before the pandemic } \\
\hline Never & $100(69.9 \%)$ \\
\hline Between $50-75 \%$ & $11(7.7 \%)$ \\
\hline Between 25-50\% & $8(5.6 \%)$ \\
\hline$<25 \%$ & $24(16.8 \%)$ \\
\hline \multicolumn{2}{|l|}{ Virtual clinical sessions during the pandemic } \\
\hline No virtual clinical sessions & $27(18.9 \%)$ \\
\hline Between $75-100 \%$ & $25(17.5 \%)$ \\
\hline Between $50-75 \%$ & $22(15.4 \%)$ \\
\hline Between 25-50\% & $22(15.4 \%)$ \\
\hline$<25 \%$ & $47(32.8 \%)$ \\
\hline \multicolumn{2}{|l|}{ Virtual bibliographic sessions during the pandemic } \\
\hline No virtual bibliographic sessions & $40(27.9 \%)$ \\
\hline Between $75-100 \%$ & $26(18.2 \%)$ \\
\hline Between $50-75 \%$ & $18(12.6 \%)$ \\
\hline Between 25-50\% & $16(11.2 \%)$ \\
\hline$<25 \%$ & $43(30.1 \%)$ \\
\hline \multicolumn{2}{|l|}{ Virtual theoretical sessions during the pandemic } \\
\hline No virtual theoretical sessions & $50(35 \%)$ \\
\hline Between $75-100 \%$ & $23(16.1 \%)$ \\
\hline Between $50-75 \%$ & $15(10.5 \%)$ \\
\hline Between $25-50 \%$ & $17(11.9 \%)$ \\
\hline$<25 \%$ & $38(26.5 \%)$ \\
\hline \multicolumn{2}{|l|}{ Acceptance of virtual training activities } \\
\hline All activities should be virtual & $7(4.9 \%)$ \\
\hline Some activities might be virtual & $112(78.3 \%)$ \\
\hline All activities should be face-to-face & $24(16.8 \%)$ \\
\hline Virtual surgery might be a useful tool & $16\left(11^{\prime} 2 \%\right)$ \\
\hline \multicolumn{2}{|l|}{ Research activities } \\
\hline Number of research projects unaffected & $60(41.9 \%)$ \\
\hline Number of research projects delayed & $53(37.1 \%)$ \\
\hline Number of research projects abandoned & $13(9.1 \%)$ \\
\hline Maintenance of oral communications and posters in congresses & $71(4.9 \%)$ \\
\hline Reduction of oral communications and posters in congresses & $53(37.1 \%)$ \\
\hline Cancellation of oral communications and posters in congresses & $7(4.9 \%)$ \\
\hline Number of residents who increased their participations in virtual congresses & $10(7 \%)$ \\
\hline
\end{tabular}

\section{Figures}

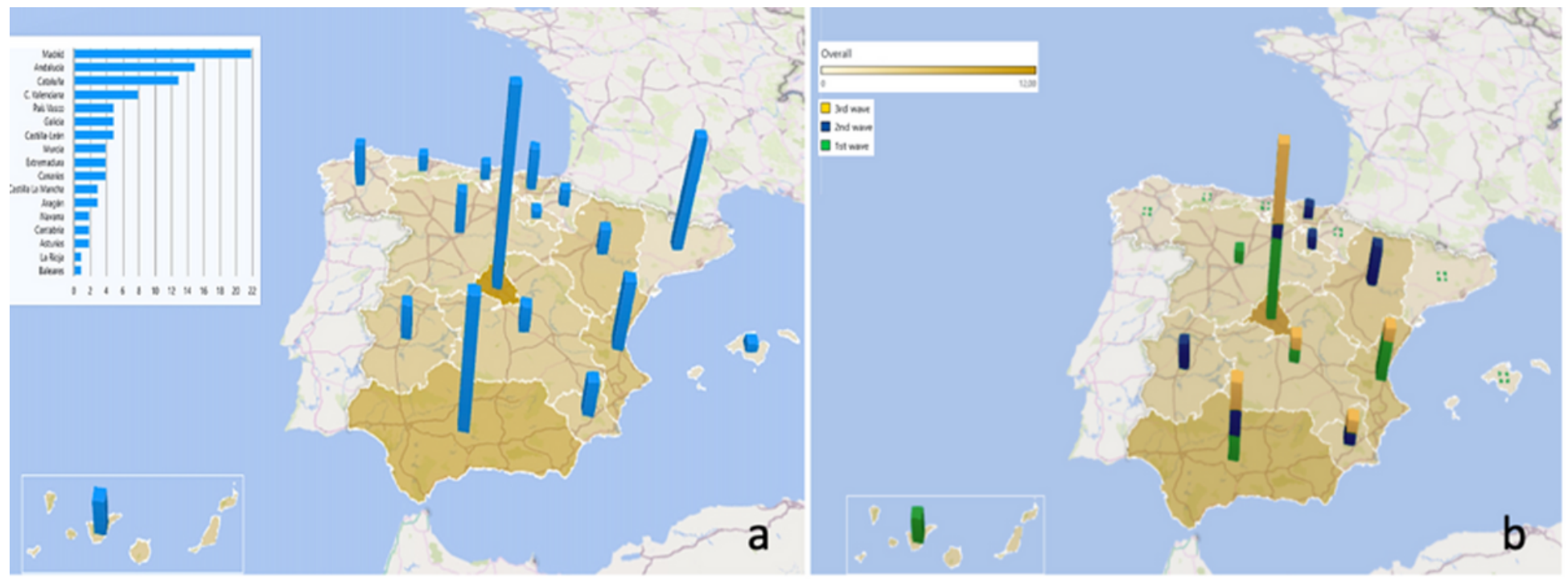


Figure 1

a) Number of residents carrying out their ENT training in each region of Spain; b) Number of residents affected by the COVID-19 in total (on the surface) and in each wave (in columns)

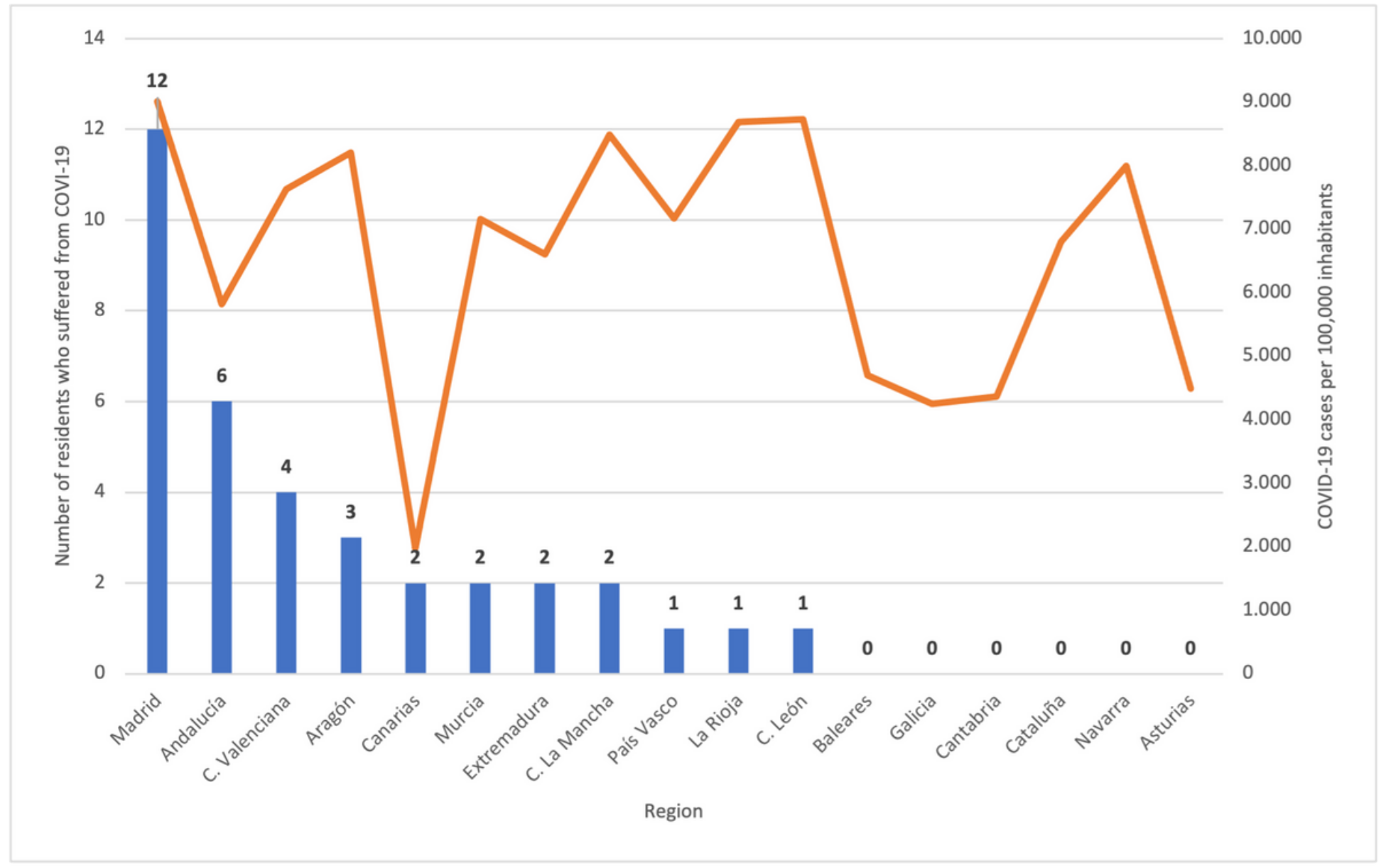

\section{Figure 2}

Correlation between the number of residents who suffered from COVID-19 and the accumulated incidence per 100,000 inhabitants. 


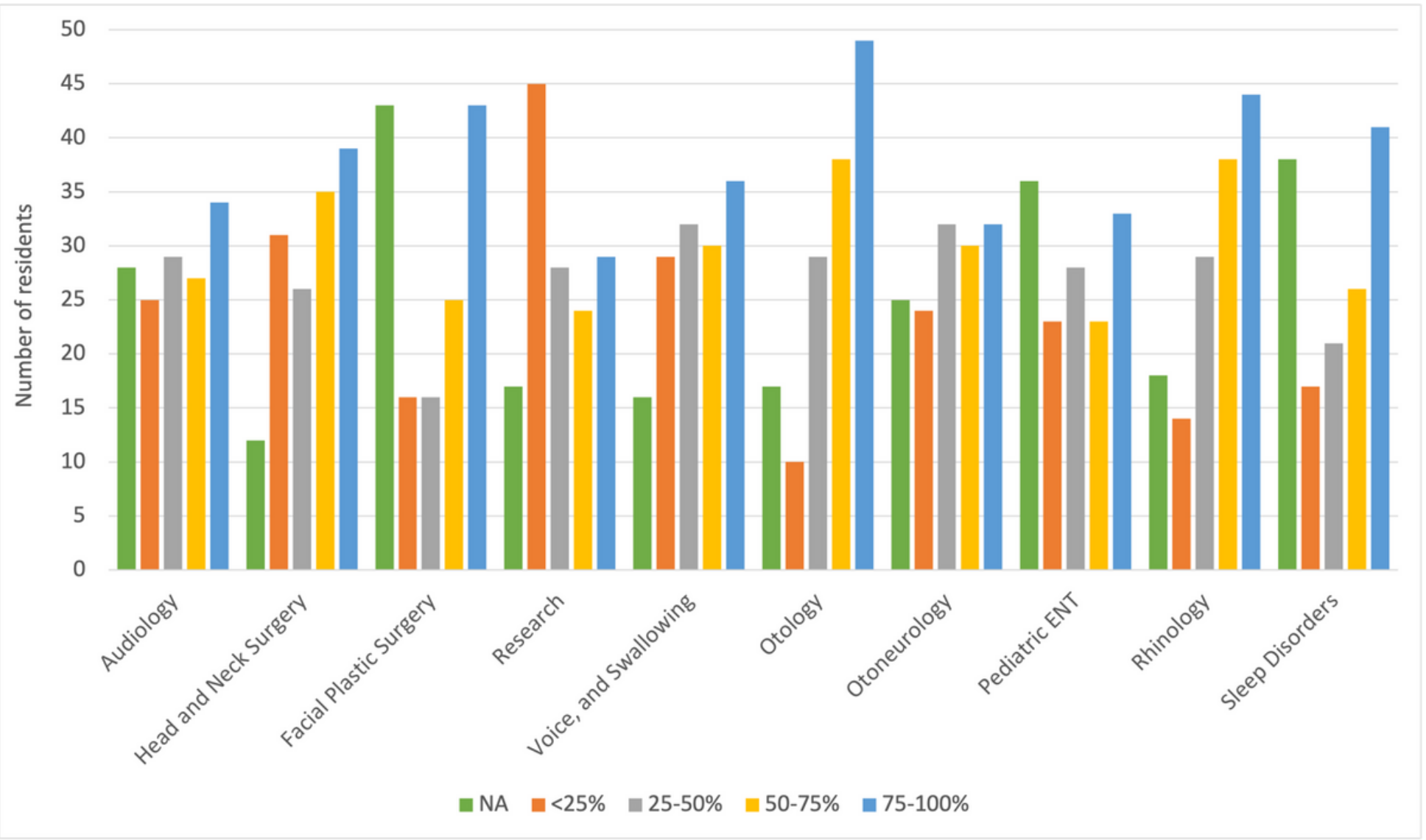

Figure 3

COVID-19 global impact (theoretical and hands-on training activities) on otolaryngology subspecialties. Accumulated number of residents in each subspecialty.

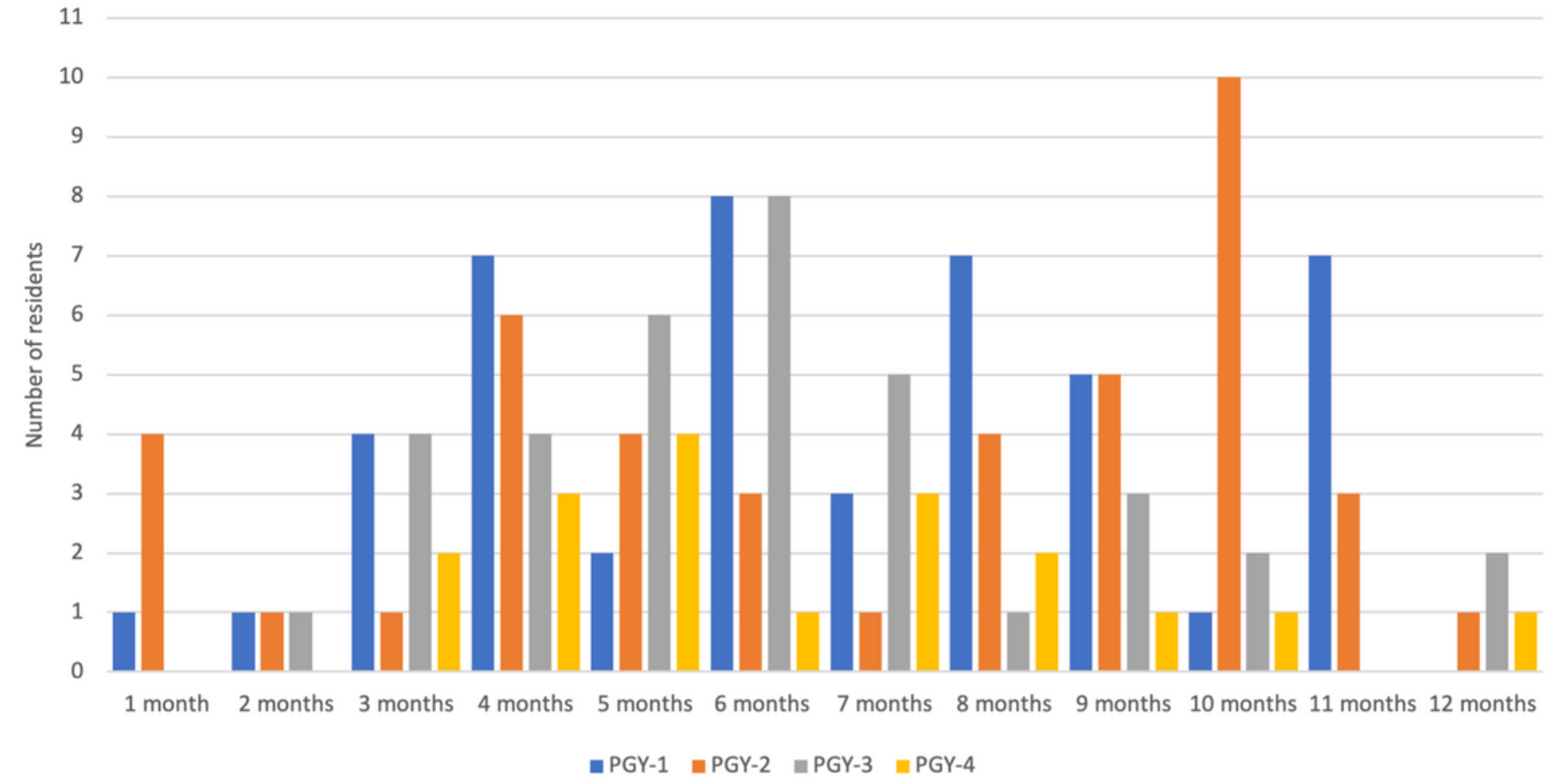

Figure 4

Perception of loss of time on residents' training due to the impact of COVID-19 